\title{
Thermal sensitivity of uncoupling protein expression in polar and temperate fish
}

\author{
Felix C. Mark *, Magnus Lucassen, Hans O. Pörtner \\ Alfred-Wegener-Institut für Polar-und Meeresforschung, Physiologie mariner Tiere, Postfach 1201 61, D-27515 Bremerhaven, Germany
}

Received 9 June 2006; received in revised form 6 August 2006; accepted 7 August 2006

Available online 10 August 2006

\begin{abstract}
Uncoupling proteins (UCP), capable of increasing proton leakage across the inner mitochondrial membrane, may play a role in the temperature-dependent setting of energy turnover in animals (and their mitochondria). Therefore, the genes and expression of fish UCP were investigated in the Antarctic eelpout Pachycara brachycephalum and a temperate confamilial species, the common eelpout Zoarces viviparus. UCP full-length cDNA was amplified from liver and muscle using RT-PCR and rapid amplification of cDNA ends (RACE). The fish UCP mRNA consists of 1906 bp in P. brachycephalum and of 1876 bp in Z. viviparus. Both zoarcid sequences contain open reading frames of 939 bp, encoding 313 amino acids, with $98 \%$ and $99 \%$ identity, respectively. Protein sequences of zoarcid UCP are closest related to fish and mammalian $\mathrm{UCP} 2$. For analysis of temperature-dependent expression common eelpouts were cold-acclimated from $10{ }^{\circ} \mathrm{C}$ to $2{ }^{\circ} \mathrm{C}$ and Antarctic eelpouts were warm-acclimated from $0{ }^{\circ} \mathrm{C}$ to $5{ }^{\circ} \mathrm{C}$. Identical cDNA probes for both species were developed to investigate fish UCP mRNA expression, and protein expression levels were detected by Western Blot in the enriched membrane fraction. During cold-acclimation in Z. viviparus, mRNA levels increased by a factor up to 2.0, protein levels increased up to 1.5, in line with mitochondrial proliferation during cold-acclimation. Despite decreased mitochondrial protein content, in Antarctic eelpout UCP levels rose upon warm acclimation by a factor up to 2.0 (mRNA) and 1.6 (protein), respectively. Besides the ongoing discussion of UCP function in vertebrates, the data are indicative of a significant role of fish UCP in thermal adaptation of fish mitochondria.
\end{abstract}

(C) 2006 Elsevier Inc. All rights reserved.

Keywords: Zoarcidae; Antarctic fish; Uncoupling proteins; Temperature acclimation; Warm stress; Mitochondrial energy metabolism

\section{Introduction}

Since the discovery of the first uncoupling protein (UCP1) in mammalian brown adipose tissue (BAT) (Nicholls et al., 1978), the various roles of UCPs have been widely discussed, with particular respect to their implications for energy metabolism. UCP1 belongs to the family of mitochondrial membrane transporter proteins (Walker, 1992) and provides a channel for protons, which flow back in after having been pumped out of the mitochondrial matrix by the enzymes of the electron transport chain (this has been termed 'proton leak'). By dissipating the electrochemical proton gradient, which drives mitochondrial ATP synthesis over the $\mathrm{F}_{0} \mathrm{~F}_{1}$-ATPase, UCP1 reduces aerobic ATP formation of the cell (Skulachev, 1998; Porter, 2001).

\footnotetext{
* Corresponding author. Tel.: +49 4714831 1015; fax: +49 47148311149

E-mail address: fmark@awi-bremerhaven.de (F.C. Mark).
}

In hibernators and small mammals, UCP1 is an accepted mediator of proton leak (Ricquier and Bouillaud, 2000) but is restricted to BAT and has a clear role in thermoregulation by heat generation. Homologues of UCP1 have been identified in various mammalian tissues (Fleury et al., 1997; Damon et al., 2000; Nakatani et al., 2002; Jastroch et al., 2004), but also in birds (Raimbault et al., 2001; Vianna et al., 2001; Talbot et al., 2004), plants (Laloi et al., 1997; Maia et al., 1998; HourtonCabassa et al., 2004), protists (Jarmuszkiewicz et al., 1999) and fungi (Jarmuszkiewicz et al., 2000), thus suggesting a more central role for the UCP family in metabolism. The specific nature of the UCP isoforms as proton channels, however, is less well established. Further mitochondrial anion carriers may be involved in proton leak, such as the adenine nucleotide translocase (Wojtczak and Wiecedilckowski, 1999), the glutamate/aspartate antiporter and the dicarboxylate carrier (Skulachev, 1998) as well as the transhydrogenase (Pörtner et al., 
2000; Jackson, 2003). They may all play a role in proton leakage and could at least contribute to set its basal rates.

A number of UCP homologues have also been identified in zebrafish (Danio rerio) and carp (Cyprinus carpio) (Stuart et al., 1999), red sea bream (Pagrus major) (Liang et al., 2003), and pufferfish (Fugo rubripes) (Jastroch et al., 2005). However, it is unlikely that UCPs of most water breathing ectotherms have a role in thermoregulation; because of the high thermal capacity of water, any metabolic heat is instantly lost over the gills. Only in tuna and shark red muscle, some heat is conserved inside the body causing regional endothermy that has been related to proton leak (Stevens et al., 2000; Duong et al., 2006). In their habitats, ectothermal fish can experience wide fluctuations of ambient water temperature, and as the rate of their metabolic reactions follows temperature passively, they have to adjust metabolic energy supply according to energy demand (Hochachka and Somero, 2002; Pörtner et al., 2005). Due to their energy dissipating potential, UCP homologues in ectotherms might thus be involved in metabolic processes related to thermal adaptation.

Very little is known about the temperature sensitivity of UCP expression and its physiological regulation in ectotherms (protists: Jarmuszkiewicz et al., 2004, molluscs: Sokolova and Sokolov, 2005). In a first study for common carp, gene expression of UCP1 was changed in response to cold, whereas UCP3 mRNA levels were changed due to fasting (Jastroch et al., 2005). Since mRNA levels have frequently been found not to be tightly correlated to protein levels (Lucassen et al., 2003), the functional consequences of the observed changes in carp remained obscure. Unlike UCP1 and UCP3, UCP2 was expressed in all investigated fish tissues (Jastroch et al., 2005), and may therefore serve as a better candidate for the general regulation of temperature-related mitochondrial function.

This study investigates a putative role for UCP2 in temperature adaptation of two closely related members of the ubiquitous fish family Zoarcidae from different thermal habitats, the eurythermal common eelpout (Zoarces viviparus) and the stenothermal Antarctic eelpout (Pachycara brachycephalum). Both species have served as model organisms in a number of studies with special regard to thermal adaptation in ectotherms (Hardewig et al., 1999a,b; Lucassen et al., 2003; Lannig et al., 2004, 2005; Heise et al., 2006). In the sluggish benthic zoarcids, white muscle tissue is hypometabolic in relation to aerobic organs like the heart, while liver is a metabolically very active organ and over a temperature range can undergo large changes in size and function, for example when serving as a lipid depot. This study is the first to provide detailed insight into temperature-dependent fish UCP expression in a temperate- and a cold-adapted model species.

\section{Materials and methods}

\subsection{Animals}

Eurythermal common eelpouts $Z$. viviparus from the Baltic Sea (mass: $100.9 \mathrm{~g} \pm 35.3 \mathrm{~g}$ ) were caught during summer 2001 in the Kieler Förde. Fish were kept at 13\% salinity, and were acclimated to $2.0 \pm 0.5{ }^{\circ} \mathrm{C}$ (cold-acclimated) or $10.5 \pm 0.5{ }^{\circ} \mathrm{C}$ (habitat temperature) for at least 2 months. Benthic Antarctic eelpouts, $P$. brachycephalum, were caught at a depth of $500 \mathrm{~m}$ close to King George Island (Antarctic Peninsula) during the cruise ANT XIX of the German research vessel "Polarstern" in April/May, 2001. Fish (mass: $58.9 \mathrm{~g} \pm 7.3 \mathrm{~g}$ ) were transferred to Bremerhaven and kept in well-aerated water of $0.0 \pm 0.5{ }^{\circ} \mathrm{C}$ (habitat temperature) and $5.0 \pm 0.5{ }^{\circ} \mathrm{C}$ (warm-acclimated) at $32-34 \%$ salinity for at least 2 months. All fish were kept under a 12:12-h light-dark cycle and were fed shrimps ad libitum once a week. Feeding was terminated 7 days prior to experimentation.

\subsection{RNA isolation}

Animals were anaesthetised with MS-222 (3-amino-benzoicmethanosulfonate, $0.5 \mathrm{~g} / \mathrm{l})$ before being killed. Samples of different tissues were quickly removed, placed in sterile $1.5 \mathrm{ml}$ tubes and were frozen immediately in liquid nitrogen. Until used for RNA or protein isolation, the samples were stored at $-80{ }^{\circ} \mathrm{C}$.

For quantitative isolation of total RNA from frozen tissue the peqgold TriFast kit (Peqlab Biotechnologie GmbH, Erlangen, Germany) was used. For the preparation of cDNA, total RNA was isolated with the RNeasy kit, and mRNA was isolated using the Oligotex mRNA kit (both kits from Qiagen, Hilden, Germany). mRNA quality and quantity was verified previous to experimentation according to standard methods (Sambrook et al., 1989).

\subsection{Characterisation of the fish UCP genes}

Fragments of the fish UCP gene were isolated by means of reverse transcription followed by PCR (RT-PCR). Primers were designed using the MacVector 7.2 program package (Accelrys, Cambridge, UK), using highly conserved regions of published sequences of the carp and zebra fish UCP2 gene (Stuart et al., 1999) as a reference. Reverse transcription was performed with Superscript RT (Invitrogen, Karlsruhe, Germany) and gene specific primers (for all primer details, see Table 1) according to the manufacturer's instructions with mRNA as templates. In the following PCR, primer pair 1 (primers $1 / 2$, cf. Table 1 ) resulted in a 440-nucleotide fragment (cf. Fig. 1) and primer pair 2 (primers 3/4) in an overlapping second fragment of 550 nucleotides.

The cDNA was amplified with Taq-Polymerase (Invitrogen, Karlsruhe, Germany) in the presence of $1.5 \mathrm{mM} \mathrm{MgCl}_{2}(\mathrm{PCR}$ conditions: $1 \mathrm{~min}$ denaturation at $94{ }^{\circ} \mathrm{C}, 1 \mathrm{~min}$ annealing at $59{ }^{\circ} \mathrm{C}$ and 1 min elongation at $72{ }^{\circ} \mathrm{C}, 30$ cycles followed by a final amplification step of $8 \mathrm{~min}$ at $72{ }^{\circ} \mathrm{C}$ ). Purification of the PCR fragments, cloning and isolation of plasmids were essentially done as described earlier (Lucassen et al., 2003). Positive clones were sequenced by MWG Biotech (Ebersberg, Germany). The full-length cDNA was determined by means of the RACE technique (rapid amplification of cDNA ends), using the RLM-RACE kit (Ambion, Austin, TX, USA) according to 
Table 1

All primers used in this study

\begin{tabular}{|c|c|c|c|c|}
\hline Primer & Name & Sequence $\left(5^{\prime}\right.$ to $\left.3^{\prime}\right)$ & Origin & Reference \\
\hline 1 & UCP2-F1 & CCACTGGACACYGCAAAAGTTAG & $410-432$ of D. rerio UCP2 & Stuart et al., 1999 \\
\hline 2 & UCP2-B2 & CAAACCACGAAACCCCTCTTCC & $841-820$ of $D$. rerio $\mathrm{UCP} 2$ & Stuart et al., 1999 \\
\hline 3 & UCP2-F8 & GATTCKGTCAAGCAGTTYTACACC & $617-640$ of $D$. rerio $\mathrm{UCP} 2$ & Stuart et al., 1999 \\
\hline 4 & UCP2-12 & CATAACCACATTCCAGGAGCCC & $1177-1156$ of $D$. rerio $\mathrm{UCP} 2$ & Stuart et al., 1999 \\
\hline 5 & UCP2-RACE-F2 & CGATTTCATCAAGGATTCCCTC & $1067-1088$ of $Z$. viviparus $\mathrm{UCP} 2$ & - \\
\hline 6 & UCP2-RACE-F3 & AAGTCCACTCCCCTGACAGACAAC & $1092-1115$ of $Z$. viviparus UCP2 & - \\
\hline 7 & UCP2-RACE-F4 & CTGCCCTGCCACTTTGTATC & $1117-1135$ of $Z$. viviparus $\mathrm{UCP} 2$ & - \\
\hline 8 & UCP2-RACE-B2 & TGTAGGCTGAGCAAAAGCAACC & $884-863$ of $Z$. viviparus $\mathrm{UCP} 2$ & - \\
\hline 9 & UCP2-RACE-B6 & CCACGGATGCCTTCTTCTTTAGC & 997-975 of Z. viviparus UCP2 & - \\
\hline 10 & $\mathrm{UCP} 2-\mathrm{Pb} / \mathrm{Zv}-\mathrm{F} 2$ & GCCATGGCGGTTGCTTTTGCTC & $856-877$ of $Z$. viviparus UCP2 & - \\
\hline 11 & $\mathrm{UCP} 2-\mathrm{Pb} / \mathrm{Zv}-\mathrm{B} 1$ & ATGCCTTCTTCTTTAGCAATGGTCTTG & 992-966 of Z. viviparus UCP2 & - \\
\hline 12 & BACT-F4 & CTGTCCCTGTATGCCTCTGGTC & $161-182$ of $Z$. viviparus ACT-B & \\
\hline 13 & BACT-B11 & GTCACGCACGATTTCCCTCTC & 372-351 of Z. viviparus ACT-B & \\
\hline
\end{tabular}

the manual. 3' RACE forward primers and 5' RACE reverse primers were designed based on cDNA fragments identical for both eelpout species (cf. Fig. 1; Table 1, primers 5-9). Cloning and sequencing of the fragments was done following the same protocols as outlined above. Sequences were assembled in MacVector to yield the full-length cDNA sequence of a fish UCP for $P$. brachycephalum and $Z$. viviparus. The cDNA sequences can be obtained under GenBank accession no. AY625190 (ZvUCP2) and GenBank accession no. AY625191 (PbUCP2). To locate putative transmembrane helices, analyses of hydrophilicity after van Heijne and Kyte-Doolittle were carried out using the MacVector program package, which was also used for analysis of phylogenetic relationships within a number of UCP homologues.

For quantification of mRNA expression, probes were constructed as outlined above using primer pair 10/11 (cf. Table 1) to yield a $137 \mathrm{bp}$ fragment for UCP and primer pair 12/ 13 resulting in a $215 \mathrm{bp}$ fragment for $\beta$-actin. Primers were designed with the MacVector program package, within a given region that was identical in both species. Plasmids containing the respective PCR fragments were obtained as described above.

\subsection{Quantification of fish UCP $m R N A$}

Ribonuclease protection assays (RPA) were performed with the RPA-III kit from Ambion (Austin, TX, USA). Total RNA $(10 \mu \mathrm{g})$ was simultaneously hybridised at $42{ }^{\circ} \mathrm{C}$ to antisense probes for fish UCP (UCP2) and $\beta$-actin (ACT-B), in case of liver RNA, or fish UCP and 18S-rRNA (18S), for muscle RNA, respectively. Identical probes were used in both species and synthesised by in vitro transcription with $\mathrm{T} 7$ or T3 RNA Polymerase (Invitrogen, Karlsruhe, Germany) with the plasmids, containing the respective cDNA fragments (described above). For 18S-rRNA, a commercial plasmid containing a highly conserved $80 \mathrm{bp}$ fragment (pTRI RNA 18S, Ambion, Austin, TX, USA) was used. All probes were labelled with $\alpha-{ }^{32} \mathrm{P}$ uridine $5^{\prime}$-triphoshate (Amersham Biosciences, Freiburg, Germany). To equalise protected fragment intensities, a specific radioactivity of $570 \mathrm{Ci} / \mathrm{mmol}$ was used for fish $\mathrm{UCP}, 45 \mathrm{Ci} /$ mmol for ACT-B and $0.1 \mathrm{Ci} / \mathrm{mmol}$ for $18 \mathrm{~S}$, respectively. The probes were always prepared freshly and purified by polyacrylamide gel electrophoresis (PAGE) under denaturing conditions ( $8 \mathrm{M}$ urea, 5\% acrylamide gel with $1 \times$ TBE running buffer Sambrook et al., 1989). The DNA templates were removed prior to electrophoresis by DNase I treatment (Invitrogen, Karlsruhe, Germany).

The RPA was optimised according to manufacturers' instructions with an RNaseA/T1 dilution of 1:50. After RNase treatment the RNA:RNA hybrids were co-precipitated with yeast RNA. The RNA was dissolved in $6 \mu \mathrm{l}$ loading dye and separated by denaturing PAGE ( $8 \mathrm{M}$ urea, 5\% acrylamide gel with $1 \times$ TBE running buffer). The size of the protected fragments corresponded to the size of the cloned PCR fragments. All probes were tested in separate lines to ensure that no background bands interfered with another probe.

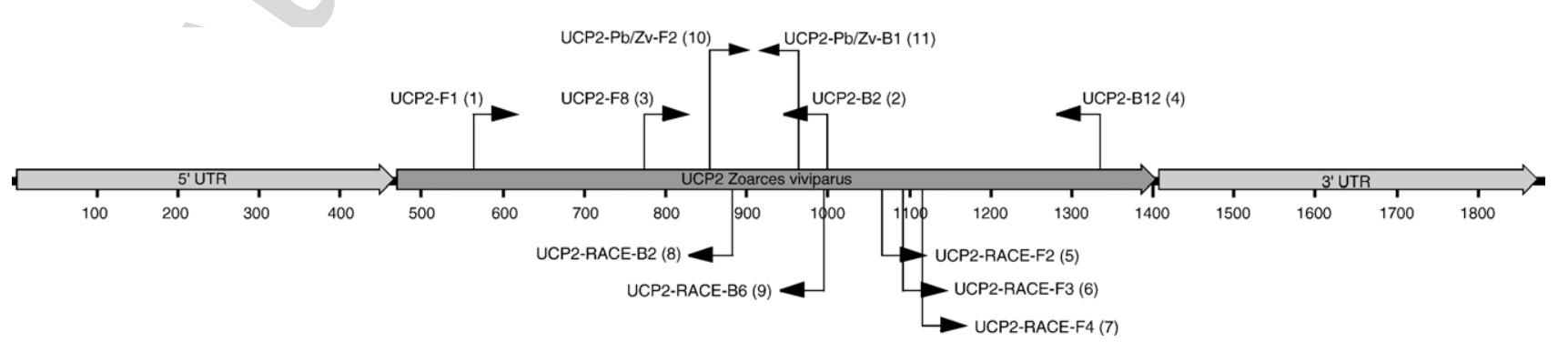

Fig. 1. Schematic overview of the Z. viviparus UCP2 cDNA. The open reading frame is shaded in dark grey, the $5^{\prime}$ and $3^{\prime}$ untranslated regions in lighter grey. The arrows indicate the positions of the primers used (see Materials and methods). 
Primary assays have been performed to ensure the specificity of the signal by means of unrelated RNA; serial dilutions were used to determine the amount of probe needed for a linearly correlated signal. After drying the gel radioactivity was detected and quantified with a phosphorous storage image system (FLA5000; Fuji, Tokyo, Japan) and the AIDA software package (raytest, Straubenhardt, Germany).

\subsection{Protein isolation, gel electrophoresis and Western Blot analysis}

Membrane enrichments were prepared from frozen tissue (about $100 \mathrm{mg}$ ) by disruption with a glass homogeniser in 15 vol. ice-cold buffer (50 mM imidazole, $\mathrm{pH} 7.4,250 \mathrm{mM}$ sucrose, $1 \mathrm{mM}$ EDTA, $200 \mu \mathrm{g} / \mathrm{ml}$ PMSF (phenyl methylsulfonyl fluoride), protease inhibitor cocktail (P-2714, SigmaAldrich, Deisenhofen, Germany), $0.1 \% \mathrm{Na}^{+}$-desoxycholate). Cellular debris was removed by low-speed centrifugation $\left(1020 \times g\right.$ for $10 \mathrm{~min}$ at $\left.0{ }^{\circ} \mathrm{C}\right)$. The membranes were pelleted from the supernatant (crude extract) by final high-speed centrifugation ( $40 \mathrm{~min}, 200,000 \times g$ at $4{ }^{\circ} \mathrm{C}$ ). The membrane pellets were resuspended in a minimum volume of homogenisation buffer ( $\sim 1 / 5$ of the starting volume). The supernatant (cytosolic proteins) was kept for comparison. Total protein was measured according to Bradford (Bradford, 1976) and a BSA standard.

Protein samples (50 $\mu \mathrm{g}$ for liver, $22.2 \mu \mathrm{g}$ for muscle) were separated by polyacrylamide gel electrophoresis (PAGE, 12\% acrylamide) under denaturing conditions (Laemmli, 1970). As heating of the samples led to high molecular mass aggregates, the samples were mixed with Laemmli's buffer and applied directly to the gel without boiling. For the determination of molecular size, a prestained marker was used (Bio-Rad, München, Germany). After electrophoresis, the proteins were transferred to PVDF membranes (Bio-Rad, München, Germany) using a trans-blot cell (Bio-Rad, München, Germany) according to the manufacturer's protocol. Blots were stained with Ponceau S to verify equal loading and successful transfer (Sambrook et al., 1989). After de-staining blots were blocked in Blotto (5\% non-fat dry milk in Tris-buffered saline with $0.1 \%(\mathrm{v} / \mathrm{v})$ Tween, $\mathrm{pH} 7.4$, TBST) for $1 \mathrm{~h}$ at room temperature. A polyclonal rabbit anti-human UCP2 antibody (UCP23-S; Alpha Diagnostic International, San Antonio, TX, USA) was used for immunodetection. To test for specificity of the UCP2 antibody, control experiments using the UCP23-S control peptide (Alpha Diagnostic International, San Antonio, TX, USA, general protocol available at: www.4adi.com/data/ abblock.html) were carried out. The blots were incubated under agitation with primary antiserum diluted in Blotto (1:2500) at $4{ }^{\circ} \mathrm{C}$ overnight. Following a series of washes with TBST, blots were incubated with mouse anti-rabbit antibody conjugated to horseradish peroxidase $(1: 2500$, diluted in Blotto; Amersham Biosciences, Freiburg, Germany) for $1 \mathrm{~h}$ at $37{ }^{\circ} \mathrm{C}$. Antibody binding was visualised by the ECL-system (Amersham Biosciences, Freiburg, Germany). Chemiluminescence was detected and quantified with a cooled CCD-camera system (LAS-1000; Fuji, Tokyo, Japan) and the AIDA software package (raytest, Straubenhardt, Germany). Normal rabbit serum (Pierce, Rockford, IL, USA) was substituted for primary antibodies to assess non-specific immunoreactivity. Membrane preparations were used to determine the optimal concentration ratio for antigen over primary and secondary antibody. For quantification, a protein concentration was used in a range where the signal changed linearly with antibody binding.

\subsection{Sample treatment and statistical analysis}

In all experiments presented here, pooled samples of five animals per treatment were used. Tissue extracts of three individual extractions were compared. To obtain a basis for statistical comparison, data from individual experiments had to be normalised. To this end, fish UCP RNA expression was normalised to the constitutively expressed $\beta$-actin in liver or 18S-rRNA in muscle, and fish UCP RNA expression was then set to 1.0 for the respective control temperature (P. brachycephalum: $0{ }^{\circ} \mathrm{C}$; Z. viviparus: $\left.10{ }^{\circ} \mathrm{C}\right)$. In the Western Blots, fish UCP signal intensities at control temperatures were normalised to 1.0 and UCP signal intensities at acclimation temperatures were put into relation to them.

Statistical analyses of differences among treatments by $t$ tests were carried out using Prism 4.0a (GraphPad Software, Inc.). Differences were considered significant if $p<0.05$. All data are presented as values \pm standard deviation (S.D.), unless stated otherwise.

\section{Results}

\subsection{Fish UCP sequence and protein specifications}

RT-PCR using the primer pairs $1 / 2$ and $3 / 4$ yielded the expected $440 \mathrm{bp}$ and $550 \mathrm{bp}$ fragments, respectively. Completion of the sequences by RACE using the specific $3^{\prime}$ forward primers 5, 6, 7 and the specific $5^{\prime}$ backward primers 8 , and 9 (see Table 1 and Fig. 1) resulted in a number of overlapping fragments, which were assembled to receive the complete sequence of the transcripts. In $P$. brachycephalum, the fish $\mathrm{UCP} 2$ transcript consists of $1906 \mathrm{bp}$; the gene of $Z$. viviparus is somewhat shorter and consists of $1876 \mathrm{bp}$. Both genes contain an open reading frame of $939 \mathrm{bp}$, encoding 313 amino acids. The complete transcript sequences are $95 \%$ identical, the coding regions 98\% (925/939 bp), and the deduced protein sequences are $99 \%$ identical with only two exchanged amino acids in 313 (P. brachycephalum/Z. viviparus: Phe259Leu and Thr311Ile) (cf. Fig. 2). The three mitochondrial transporter protein signature motifs found in all members of the mitochondrial transporter protein family (Walker, 1992) are present in $P$. brachycephalum and $Z$. viviparus UCP2 (cf. Fig. 2) and identical to the motifs found in rat UCP2 and the known fish UCP2s (Stuart et al., 1999; Liang et al., 2003). The zoarcid UCP2 consists of three repeated motifs of about $100 \mathrm{bp}$, each containing two membrane helices, again typical for this protein family. Six putative membrane helices (predicted by MacVector and www.predictprotein.org) are indicated in Fig. 2. The total 


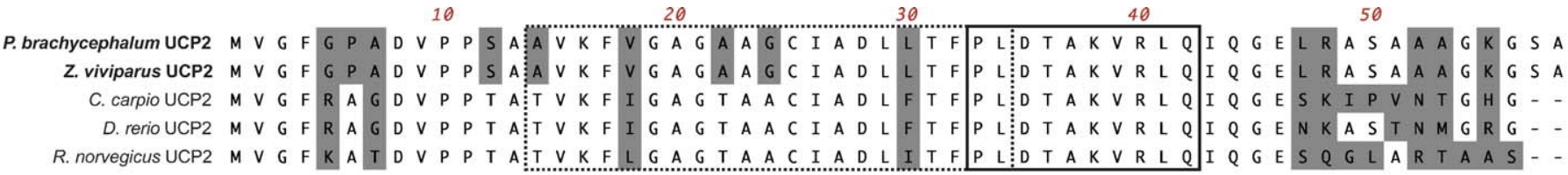

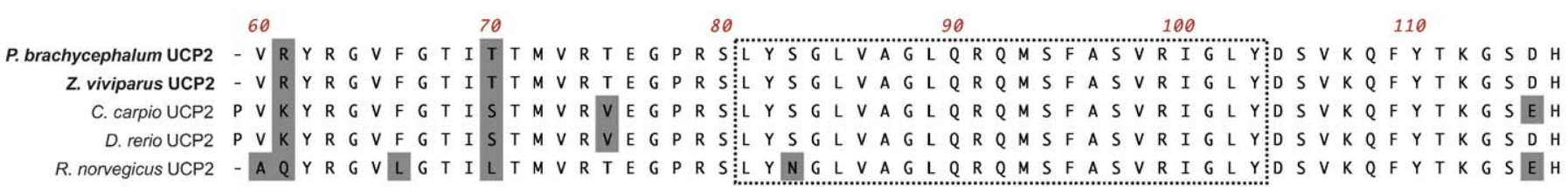

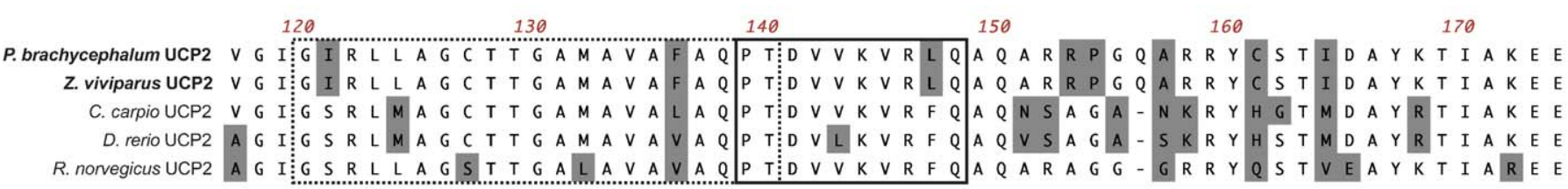

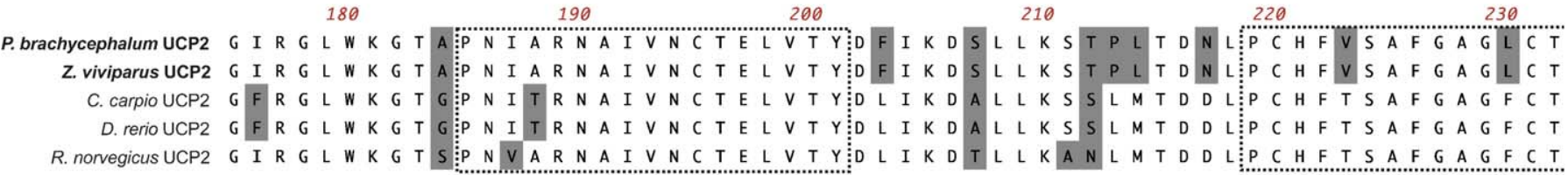

P. brachycephalum UCP2 T T V T A S P V D V V K T R Y M N A A L G Q Y S S V F N C A A A M M N K E G P LA A F K G F M P S F L R L G S W N V V

P. brachycephalum UCP2 TT V T A S P V D V V K T R Y M N A A L G Q Y S S V F N C A A A M M N K E G P L A F Y K G F M P S F L R L G S W N V V

P. brachycephalum UCP2 TT V T A S P V D V V K T R Y M N A A L G Q Y S S V F N C A A A M M N K E G P L A F Y K G F M P S F L R L G S W N V V Z. viviparus UCP2 T V T A S P V D V V K T R Y M N A A L G Q Y S S S V L N C A A A M M M N K E E G P L A F Y K K G F M P S F L R L G S W N V V C. carpio UCP2 T V I A S P V D D V K T R Y M N S A P G Q Y C S A L N C A V A M L T K E G P K A F Y K G F M P S F L R L G S W N V V D. rerio UCP2 T I I A S P V D V V K T R Y M N S A Q G Q Y S S A L N C A V A M L T K K G P K A A F F K G F M P S F L R L G S W N V V

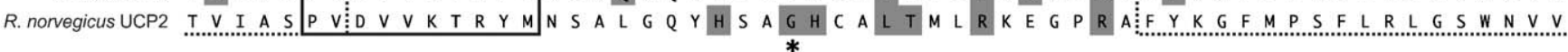

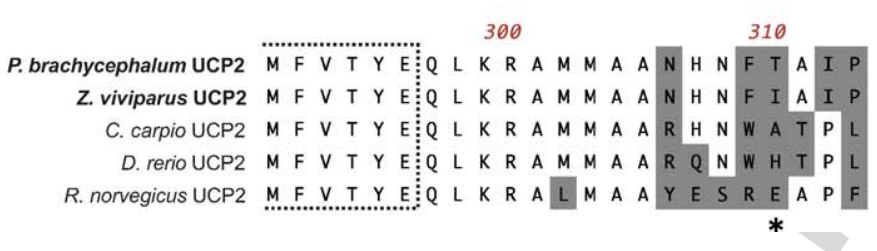

Fig. 2. Alignment of fish UCP2 peptide sequences of the two zoarcids P. brachycephalum and Z. viviparus, carp (C. carpio) and zebrafish (D. rerio) and rat (R. norvegicus). Amino acid exchanges are highlighted in grey, exchanges between $P$. brachycephalum and $Z$. viviparus are additionally marked with an asterisk. Solid boxes indicate signature motifs of the mitochondrial transporter protein family; dashed boxes depict putative transmembrane helices.

protein sequence of zoarcid UCP2 is $77 \%$ identical to rat UCP2 ( $85 \%$ similarity) and $75-79 \%$ to those of zebrafish (D. rerio), carp (C. carpio) and red sea bream (P. major) $(85-87 \%$ similarity). The phylogenetical reconstruction in Fig. 3 depicts the close relationship to carp and zebrafish UCP2 proteins and to the mammalian, marsupialian and amphibian UCP2s. The encoding cDNA regions bear $73-75 \%$ identity to carp and zebrafish cDNA and $71 \%$ identity to rat UCP2 cDNA, while the complete transcripts bear $47-50 \%$ identity to carp and zebrafish cDNA and $34 \%$ to rat cDNA.

\subsection{Temperature-dependent UCP expression}

Total RNA concentrations isolated from liver and muscle were comparable to earlier results (Hardewig et al., 1999b; Lucassen et al., 2003) and did not change significantly during acclimation. Also, liver sizes did not change during acclimation. Specific expression of the fish UCP2 genes was determined using ribonuclease protection assays (RPA). Fig. 4 depicts a typical autoradiography of an RPA of fish UCP2
mRNA expression in the liver of cold- and warm-acclimated common eelpout, Z. viviparus. Fish UCP2 mRNA expression was detected with the $137 \mathrm{bp}$ UCP probe relative to the expression of $\beta$-actin (215 bp probe), and expression levels were normalised to the particular habitat temperatures of the fish. During cold acclimation, relative expression levels in $Z$. viviparus liver tissue rose two-fold from $1.0 \pm 0.34$ at $10{ }^{\circ} \mathrm{C}$ to $2.07 \pm 0.56$ at $2{ }^{\circ} \mathrm{C}$ (Fig. 5A), while they were slightly increased in muscle tissue by a factor $1.5(1.0 \pm 0.05$ to $1.55 \pm$ 0.19) (Fig. 5B). In contrast, a 2-fold increment was detectable after warm acclimation in muscle $(1.0 \pm 0.16$ to $1.98 \pm 0.15)$, and a less pronounced increment in liver $\left(1.0 \pm 0.09\right.$ at $0{ }^{\circ} \mathrm{C}$ to $1.33 \pm 0.20$ at $5^{\circ} \mathrm{C}$ ) in the Antarctic eelpout P. brachycephalum (Fig. 6A and B). All increases were statistically significant $(p<0.05)$.

To determine whether these increments in transcript levels have led to comparable changes in protein level, the respective protein levels were quantified with polyclonal antibodies raised against the human UCP2 protein. Fig. 6 represents a typical Western Blot of liver protein extracts of $Z$. viviparus and 


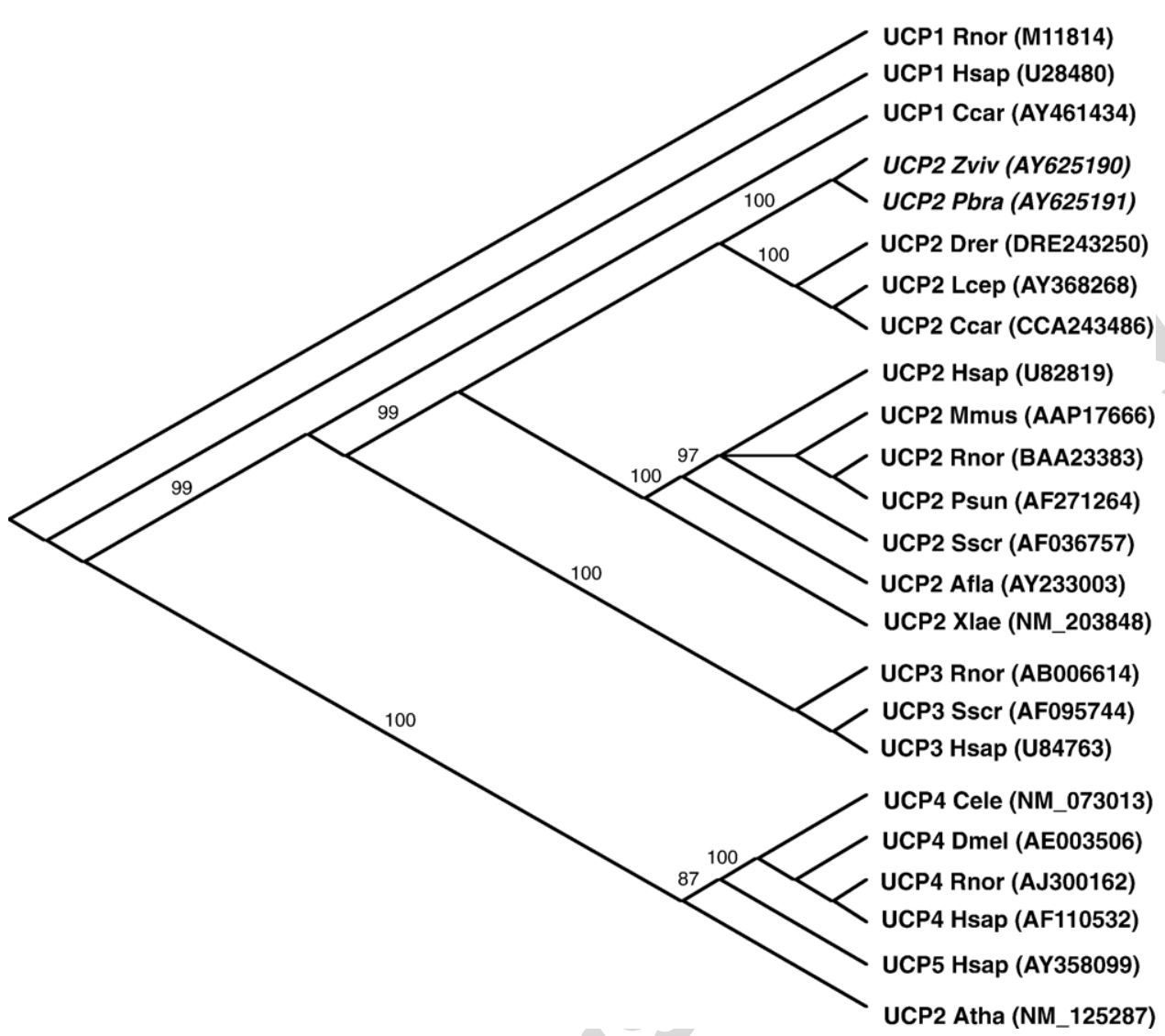

Fig. 3. Phylogenetic reconstruction of the fish uncoupling proteins in relation to the mammalian isoforms. The tree was calculated using the Neighbour Joining method (bootstrap (1000 replicates); tie breaking=systematic; Distance: uncorrected (' $p$ '); Gaps distributed proportionally). The proteins from $P$. brachycephalum and $Z$. viviparus group with all other known fish UCP2, and are closest related to the mammalian UCP2. Accession numbers of the respective genes are given in parentheses. Abbreviations: Rnor: Rattus norvegicus; Hsap: Homo sapiens; Ccar: Cyprio carpio; Zviv: Zoarces vivparus; Pbra: Pachycara brachycephalum; Drer: Danio rerio; Lcep: Leuciscus cephalus; Mmus: Mus musculus; Psun: Phodopus sungorus; Sscr: Sus scrofa; Afla: Antechinus flavipes; Xlae: Xenopus laevis; Cele: Caenorhabditis elegans; Dmel: Drosophila melanogaster; Atha: Arabidopsis thaliana.

P. brachycephalum acclimated to extreme and habitat temperatures. The antibody specifically cross-reacted with a single prominent protein band of $37 \mathrm{kDa}$, which is in good agreement

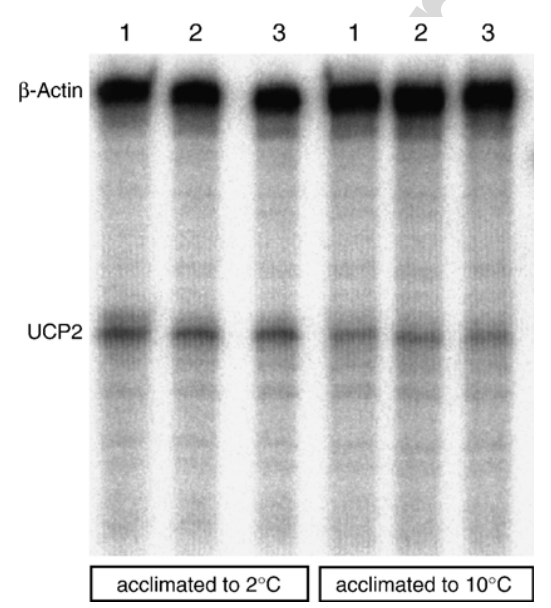

Fig. 4. Representative picture of a ribonuclease protection assay (RPA) of liver RNA samples of $Z$. viviparus, acclimated to $2{ }^{\circ} \mathrm{C}$ and $10^{\circ} \mathrm{C}$. Each lane was run with $10 \mu \mathrm{g}$ RNA, lanes 1-3 and 4-6 represent triplicates of pooled RNA $(n=5)$ of one experiment, respectively. The size of the protected beta actin fragment was $215 \mathrm{bp}$, the length of the fish UCP2 fragment was $137 \mathrm{bp}$. to the predicted size of the deduced amino acid sequence $(33,4 \mathrm{kDa})$, and could be enriched in the membrane fraction. Following addition of $50 \mu \mathrm{g}$ UCP23-S control peptide per $\mu 1$ UCP23-S antiserum, the UCP2 signal could be neutralised completely (data not shown), further supporting the specificity of the observed signals.

Fish UCP2 protein expression levels in Z. viviparus liver tissue rose during cold acclimation by a factor of $1.45(1.0 \pm$ 0.07 at $10{ }^{\circ} \mathrm{C}$ to $1.45 \pm 0.01$ at $2{ }^{\circ} \mathrm{C}$, Fig. 5C), and increased in muscle tissue by a factor of $1.3(1.0 \pm 0.14$ to $1.28 \pm 0.07)$ (Fig. 5D). In the Antarctic eelpout P. brachycephalum, we found protein levels to increase during warm acclimation to $5^{\circ} \mathrm{C}$ by a factor $1.6\left(1.0 \pm 0.13\right.$ at $0{ }^{\circ} \mathrm{C}$ to $1.58 \pm 0.001$ at $\left.5^{\circ} \mathrm{C}\right)$ in liver (Fig. 5C). Therefore, protein expression levels were in line with mRNA expression levels, differences in expression were all significant, although not quite as prominent as on mRNA level. Protein levels in P. brachycephalum muscle were only barely detectable, possibly because of very low fish UCP2 concentrations and/or lower affinity of the antibody to the UCP2 of Antarctic eelpout in the white muscle tissue. These data had therefore to be excluded. It should be noted that data presented here were normalised to visualise the differences between organs and species, thus the graphs in Fig. 5 do not 
A: UCP-2 mRNA levels in liver

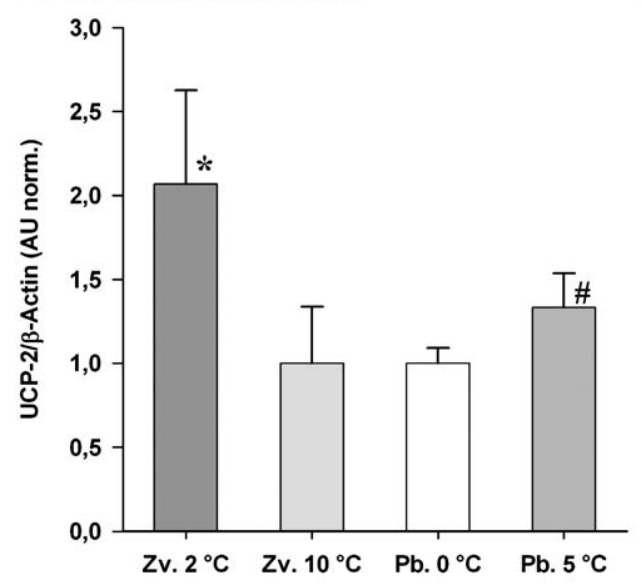

$\mathrm{C}$ : UCP-2 protein levels in liver

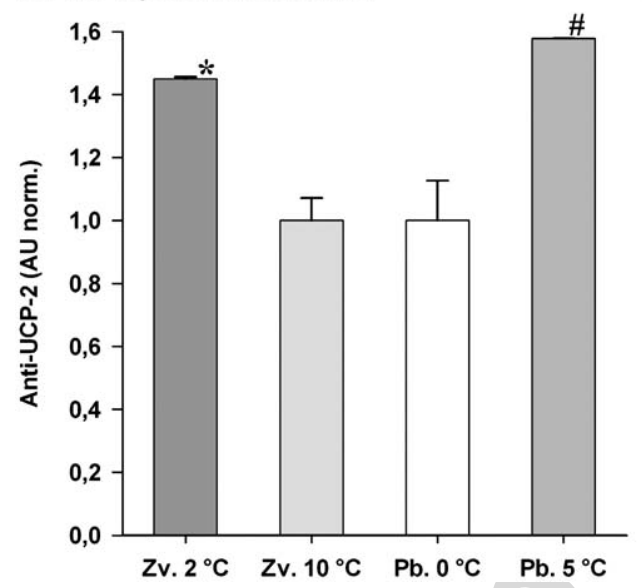

B: UCP-2 mRNA levels in muscle

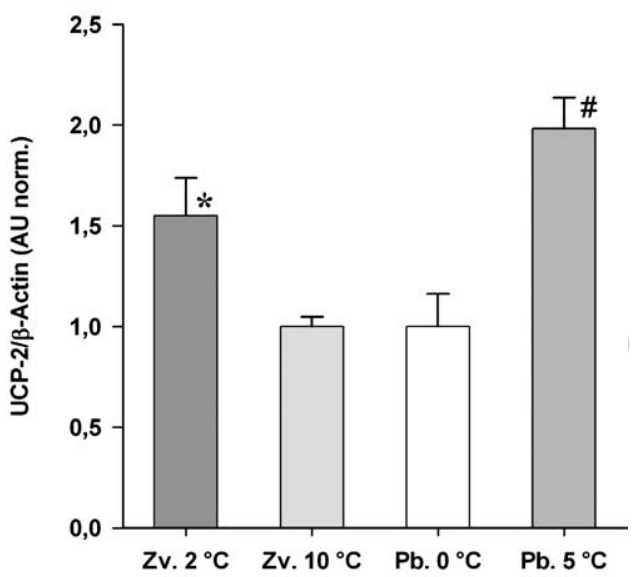

D: UCP-2 protein levels in muscle

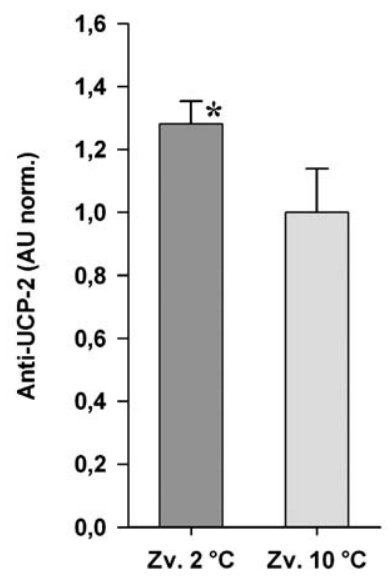

Fig. 5. Fish $\mathrm{UCP} 2 \mathrm{mRNA}$ and protein expression levels in liver and muscle of the two zoarcids $P$. brachycephalum $(\mathrm{Pb})$ and $Z$. viviparus $(\mathrm{Zv})$, acclimated to 0 and $5{ }^{\circ} \mathrm{C}$ and 10 and $2{ }^{\circ} \mathrm{C}$, in liver. D: protein expression in muscle. ${ }^{*}$ Significantly different from $\mathrm{Zv} .10{ }^{\circ} \mathrm{C}$. ${ }^{\#}$ Significantly different from Pb. $0{ }^{\circ} \mathrm{C},(P=0.05)$. Error bars represent standard deviation (S.D.).

represent actual concentrations but normalised ratios. In $P$. brachycephalum, constitutive fish UCP 2 mRNA levels were up to 6.5 times lower than in $Z$. viviparus, in muscle even more so than in liver (data not shown). This is also reflected at the

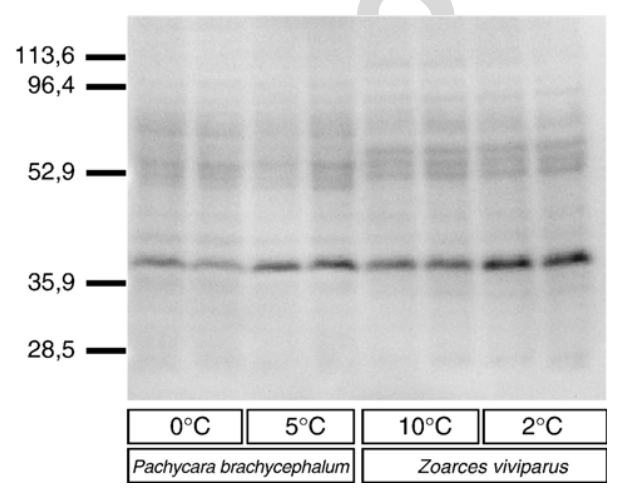

Fig. 6. Representative picture of fish UCP2 detection by Western Blot in enriched mitochondrial fractions from liver of the two zoarcids $P$. brachycephalum and $Z$. viviparus, acclimated to 0 and $5^{\circ} \mathrm{C}$ and 10 and $2{ }^{\circ} \mathrm{C}$, respectively. Each lane contained $50 \mu \mathrm{g}$ of protein pooled from five individuals, lanes were run in duplicates. The anti-human UCP2 antibody bound to a protein band of approximately $37 \mathrm{kDa}$. protein level (cf. Fig. 6), although interspecies comparisons using antibodies have to be analysed with care.

\section{Discussion}

\subsection{Molecular adaptations to low temperature}

In this study, we were able to identify an uncoupling protein homologue in muscle and liver tissue of the two zoarcid species $P$. brachycephalum and $Z$. viviparus. The $\mathrm{mRNA}$ and deduced protein sequences were found to belong to the mitochondrial transporter protein family, showing highest similarities to fish and mammalian homologues of UCP2, and therefore were designated fish UCP2.

Independent of the used algorithm, the zoarcid proteins clustered together with the cyprinid and the mammalian UCP2 in the phylogenetic tree (Fig. 3). These UCP2 form a branch together with the mammalian UCP3.

Its high degree of identity (99\%) within the zoarcids and considerable similarity to fish and mammalian UCP2 (> 85\%) suggest that fish UCP2 has been much conserved over evolutionary time scales and therefore holds a position of 
significant importance in cellular energy metabolism. These findings are in line with similarly high degrees of conservation in other functionally important genes like citrate synthase, cytochrome-c oxidase subunit II (Lucassen et al., 2003) and $\mathrm{Na}^{+} / \mathrm{K}^{+}$-ATPase and $\mathrm{Na}^{+} / \mathrm{H}^{+}$exchanger (Lucassen et al., unpublished results) in teleosts and other vertebrates. The two amino acid exchanges observed (P. brachycephalum/Z. viviparus: Phe259Leu and Thr311Ile) are located outside the conserved structures towards the C-terminal end, however, their functional consequences remain unclear. Fields and Somero have shown for $\mathrm{A}_{4}$-lactate dehydrogenase of notothenioids within a latitudinal cline that minor amino acid substitutions found outside the catalytical centers can change the overall flexibility of the molecule, leading to different kinetic properties and thermal optima (Fields and Somero, 1998). The amino acid substitutions found between the eelpouts could have a similar function.

\subsection{Temperature-dependent fish UCP2 expression}

Fish UCP2 expression in zoarcids is clearly temperaturedependent; in this study we found a general up-regulation during warm and cold adaptation, respectively, in both the stenothermal Antarctic and the eurythermal common eelpout. Up-regulation includes mRNA and protein expression levels, which showed the same trends in tissues of both high and low metabolic activities. This is indicative of a general regulation pattern of the organism. Variability of mRNA and protein expression data have also been found in other studies and likely reflect regulatory flexibility on the tissue level (cf. Lucassen et al., 2003).

Higher levels of fish UCP2 can simply be the result of an overall increase in mitochondrial capacity frequently found during cold acclimation (Guderley and St-Pierre, 2002; Pörtner, 2002). For $Z$. viviparus, there is clear evidence for mitochondrial proliferation in the cold, the key enzyme of the electron transport chain, cytochrome-c oxidase has been found to increase at both message and functional levels in muscle after cold acclimation (Hardewig et al., 1999b). Activity levels of liver citrate synthase were also enhanced in the cold (Lucassen et al., 2003), implying a general augmentation of mitochondrial capacity following cold adaptation. As a result, total mitochondrial protein content in liver tissue is found to rise in the cold in Z. viviparus (Lannig et al., 2005). This is corroborated by our findings for Z. viviparus, in which fish UCP2 message and protein levels were up-regulated significantly upon cold acclimation.

Accordingly, for the Antarctic eelpout P. brachycephalum, one would expect a reduction of mitochondrial capacity in the warm, thus enhancing temperature tolerance by reducing mitochondrial maintenance costs (Pörtner, 2002). Indeed, when acclimating Antarctic eelpout $P$. brachycephalum to $5{ }^{\circ} \mathrm{C}$, Lannig et al. (2005) found decreases in mitochondrial protein content and ATP synthesis capacities in the liver, while proton leakage rates of isolated mitochondria remained more or less unchanged upon warm acclimation. Despite this general pattern of mitochondrial down regulation in the warm, in the present study fish UCP2 expression was increased at mRNA and protein level during warm acclimation in the Antarctic eelpout. Up-regulated message and protein levels suggest the potential for higher mitochondrial proton leak rates in warm acclimated $P$. brachycephalum. The reason for the discrepancy between increased fish UCP2 levels and seemingly constant proton leak rates after warm acclimation might be on the one hand located in posttranslational modifications at the protein level. For instance, Wodtke (1981a,b) found altered molecular cytochrome- $c$ oxidase activities with thermally induced membrane composition. Besides, other proteins contributing to proton leak have to be considered (cf. Introduction).

On the other hand, only lightly down-regulated mitochondrial capacities in the warm (see Lannig et al., 2005) lead to the question, whether $P$. brachycephalum lacks the adaptive plasticity to fully compensate for warming to $5{ }^{\circ} \mathrm{C}$, and proton leak is used to control a partly unbalanced increase in energy turnover during warming. In captivity, P. brachycephalum can survive for years at these temperatures and still display positive growth with an optimum close to $4{ }^{\circ} \mathrm{C}$ (Brodte et al., in press), but only at the expense of elevated metabolic costs (Mark et al., 2002; personal observation). These findings suggest that $P$. brachycephalum is not an extreme stenotherm (sensu Somero and DeVries, 1967) and may be able to in part adapt to higher temperatures than nowadays found in Antarctic waters by accordingly adjusting its metabolism exemplified by the observed fish UCP2 expression pattern. This may reflect the deep-sea origin of the species.

\subsection{Implications for UCP function in fish}

In a parallel study of the two eelpout species with comparable acclimation temperatures, Heise and coworkers (unpublished data) found patterns of oxidative stress parameters to correspond to the observed levels of fish UCP2 expression: Oxidative damage parameters indicating elevated reactive oxygen species (ROS) production were higher after warm acclimation in Antarctic eelpouts. In this cold adapted species, mitochondrial capacities might remain too high in the warm, exceeding ATP demand or supply of oxygen as final acceptor of electrons in the respiratory chain. That would lead to high membrane potentials and high reducing capacities in the respiratory chain, conditions that facilitate ROS formation. Increased ROS production in P. brachycephalum in the warm might explain elevated levels of fish UCP2 as a reaction towards oxidative stress (Echtay et al., 2002).

Skulachev (1998) suggested a role for mammalian UCP2 as a 'safety valve' in the prevention of ROS formation by mild uncoupling, a theory that was adopted by a number of authors (Brand, 2000; Pecqueur et al., 2001; Richard et al., 2001). Yet, this exclusive role for fish UCP2 remains to be investigated.

A further regulatory function has been indicated by Brand and coworkers (Rolfe and Brand, 1996; Rolfe et al., 1999): In mammalian resting skeletal muscle they found proton leak rates to be higher than in working muscle. It is possible that by regulating the degree of mitochondrial coupling, UCP controls both ATP synthesis and the prevention of ROS formation. It is 
quicker and easier to either transcriptionally (Medvedev et al., 2001) or translationally (Pecqueur et al., 2001) regulate a single protein like UCP2 instead of the suite of proteins of the electron transport chain, the more flexible mitochondrial metabolism has to be, the higher the rate of control. This is in line with a hypothesis brought forward by Hardewig et al. (1999a), who assumed that 'proton leakiness may be lower in mitochondria from Antarctic fish than in temperate fish mitochondria'. Although we found native fish UCP2 levels to be somewhat lower in P. brachycephalum than in Z. viviparus (cf. Fig. 6), there is still no evidence to unambiguously prove this hypothesis and further investigation is needed.

\section{Conclusions and perspectives}

To our knowledge, this is the first study to demonstrate temperature-dependent UCP expression in fish at both transcript and protein levels, possibly even the first such study in ectothermic vertebrates. Our findings are in line with the hypothesis that UCP holds an important position within mitochondrial energy metabolism of ectotherms, and especially during thermal stress may function as a regulatory protein, controlling the mitochondrial membrane potential to balance ROS formation and ATP production. There is, however, no evidence for a change in baseline mitochondrial proton leakage upon enhanced UCP2 expression in fish. Further work should therefore focus on a functional characterisation of UCP homologues within mitochondria. It remains to be investigated whether an evolutionary conservation of function can be found within this protein family, which is indicated by its widespread occurrence in the eukaryotic kingdom.

\section{References}

Bradford, M.M., 1976. A rapid and sensitive method for the quantitation of microgram quantities of protein utilizing the principle of protein-dye binding. Anal. Biochem. 72, 248-254.

Brand, M.D., 2000. Uncoupling to survive? The role of mitochondrial inefficiency in ageing. Exp. Gerontol. 35, 811-820.

Brodte, E., Knust, R., Pörtner, H.O., in press. Temperature dependent energy allocation to growth in Antarctic and boreal eelpout (Zoarcidae). Polar Biol. (doi:10.1007/s00300-006-0165-ys).

Damon, M., Vincent, A., Lombardi, A., Herpin, P., 2000. First evidence of uncoupling protein-2 (UCP-2) and -3 (UCP-3) gene expression in piglet skeletal muscle and adipose tissue. Gene 246, 133-141.

Duong, C.A., Sepulveda, C.A., Graham, J.B., Dickson, K.A., 2006. Mitochondrial proton leak rates in the slow, oxidative myotomal muscle and liver of the endothermic shortfin mako shark (Isurus oxyrinchus) and the ectothermic blue shark (Prionace glauca) and leopard shark (Triakis semifasciata). J. Exp. Biol. 209, 2678-2685.

Echtay, K.S., Roussel, D., St-Pierre, J., Jekabsons, M.B., Cadenas, S., Stuart, J.A., Harper, J.A., Roebuck, S.J., Morrison, A., Pickering, S., Clapham, J.C., Brand, M.D., 2002. Superoxide activates mitochondrial uncoupling proteins. Nature 415, 96-99.

Fields, P.A., Somero, G.N., 1998. Hot spots in cold adaptation: localized increases in conformational flexibility in lactate dehydrogenase A4 orthologs of Antarctic notothenioid fishes. Proc. Natl. Acad. Sci. U. S. A. 95, 11476-11481

Fleury, C., Neverova, M., Collins, S., Raimbault, S., Champigny, O., LeviMeyrueis, C., Bouillaud, F., Seldin, M.F., Surwit, R.S., Ricquier, D., Warden, C.H., 1997. Uncoupling protein-2: a novel gene linked to obesity and hyperinsulinemia. Nat. Genet. 15, 269-272.
Guderley, H., St-Pierre, J., 2002. Going with the flow or life in the fast lane: contrasting mitochondrial responses to thermal change. J. Exp. Biol. 205, 2237.

Hardewig, I., Peck, L.S., Pörtner, H.O., 1999a. Thermal sensitivity of mitochondrial function in the Antarctic notothenioid Lepidonotothen nudifrons. J. Comp. Physiol. B 169, 597-604.

Hardewig, I., Van Dijk, P.L.M., Moyes, C.D., Pörtner, H.O., 1999 b. Temperature-dependent expression of cytochrome-c oxidase in Antarctic and temperate fish. Am. J. Physiol. 277, R508-R516.

Heise, K., Puntarulo, S., Nikinmaa, M., Lucassen, M., Portner, H.O., Abele, D., 2006. Oxidative stress and HIF-1 DNA binding during stressful cold exposure and recovery in the North Sea eelpout (Zoarces viviparus). Comp. Biochem. Physiol. Part A: Mol. Integr. Physiol. 143, 494-503.

Hochachka, P.W., Somero, G.N., 2002. Biochemical Adaptation. Oxford University Press, New York.

Hourton-Cabassa, C., Rita Matos, A., Zachowski, A., Moreau, F., 2004. The plant uncoupling protein homologues: a new family of energy-dissipating proteins in plant mitochondria. Plant Physiol. Biochem. 42, 283-290.

Jackson, J.B., 2003. Proton translocation by transhydrogenase. FEBS Lett. 545, $18-24$.

Jarmuszkiewicz, W., Sluse-Goffart, C.M., Hryniewiecka, L., Sluse, F.E., 1999. Identification and characterization of a protozoan uncoupling protein in Acanthamoeba castellanii. J. Biol. Chem. 274, 23198-23202.

Jarmuszkiewicz, W., Milani, G., Fortes, F., Schreiber, A.Z., Sluse, F.E., Vercesi, A.E., 2000. First evidence and characterization of an uncoupling protein in fungi kingdom: CpUCP of Candida parapsilosis. FEBS Lett. 467, 145-149.

Jarmuszkiewicz, W., Antos, N., Swida, A., Czarna, M., Sluse, F.E., 2004. The effect of growth at low temperature on the activity and expression of the uncoupling protein in Acanthamoeba castellanii mitochondria. FEBS Lett. $569,178-184$.

Jastroch, M., Withers, K., Klingenspor, M., 2004. Uncoupling protein 2 and 3 in marsupials: identification, phylogeny, and gene expression in response to cold and fasting in Antechinus flavipes. Physiol. Genomics 17, 130-139.

Jastroch, M., Wuertz, S., Kloas, W., Klingenspor, M., 2005. Uncoupling protein 1 in fish uncovers an ancient evolutionary history of mammalian nonshivering thermogenesis. Physiol. Genomics 22, 150-156.

Laemmli, U.K., 1970. Cleavage of structural proteins during the assembly of the head of bacteriophage T4. Nature 227, 680-685.

Laloi, M., Klein, M., Riesmeier, J.W., Muller-Rober, B., Fleury, C., Bouillaud, F., Ricquier, D., 1997. A plant cold-induced uncoupling protein. Nature 389, 135-136.

Lannig, G., Bock, C., Sartoris, F.J., Pörtner, H.O., 2004. Oxygen limitation of thermal tolerance in cod, Gadus morhua L., studied by magnetic resonance imaging and on-line venous oxygen monitoring. Am. J. Physiol. 287, R902-R910.

Lannig, G., Storch, D., Pörtner, H.O., 2005. Aerobic mitochondrial capacities in Antarctic and temperate eelpout (Zoarcidae) subjected to warm versus cold acclimation. Polar Biol. 28, 575-584.

Liang, X.F., Ogata, H.Y., Oku, H., Chen, J., Hwang, F., 2003. Abundant and constant expression of uncoupling protein 2 in the liver of red sea bream Pagrus major. Comp. Biochem. Physiol. A: Mol. Integr. Physiol. 136, 655-661.

Lucassen, M., Schmidt, A., Eckerle, L.G., Pörtner, H.O., 2003. Mitochondrial proliferation in the permanent vs. temporary cold: enzyme activities and mRNA levels in Antarctic and temperate zoarcid fish. Am. J. Physiol. 285, R1410-R1420.

Lucassen, M., Sokolov, E.P., Pörtner, H.O., unpublished. Cold induced expression of the $\mathrm{Na}^{+} / \mathrm{K}^{+}$-ATPase in temperate versus cold-adapted fish.

Maia, I.G., Benedetti, C.E., Leite, A., Turcinelli, S.R., Vercesi, A.E., Arruda, P., 1998. AtPUMP: an Arabidopsis gene encoding a plant uncoupling mitochondrial protein. FEBS Lett. 429, 403-406.

Mark, F.C., Bock, C., Pörtner, H.O., 2002. Oxygen-limited thermal tolerance in Antarctic fish investigated by MRI and ${ }^{31} \mathrm{P}-\mathrm{MRS}$. Am. J. Physiol. 283, R1254-R1262.

Medvedev, A.V., Snedden, S.K., Raimbault, S., Ricquier, D., Collins, S., 2001. Transcriptional regulation of the mouse uncoupling protein-2 gene. Double E-box motif is required for peroxisome proliferator-activated receptorgamma-dependent activation. J. Biol. Chem. 276, 10817-10823. 
Nakatani, T., Tsuboyama-Kasaoka, N., Takahashi, M., Miura, S., Ezaki, O., 2002. Mechanism for peroxisome proliferator-activated receptor-alpha activator-induced up-regulation of UCP2 mRNA in rodent hepatocytes. J. Biol. Chem. 277, 9562-9569.

Nicholls, D.G., Bernson, V.S., Heaton, G.M., 1978. The identification of the component in the inner membrane of brown adipose tissue mitochondria responsible for regulating energy dissipation. Experientia, Suppl. 32, 89-93.

Pecqueur, C., Alves-Guerra, M.C., Gelly, C., Levi-Meyrueis, C., Couplan, E., Collins, S., Ricquier, D., Bouillaud, F., Miroux, B., 2001. Uncoupling protein 2 , in vivo distribution, induction upon oxidative stress, and evidence for translational regulation. J. Biol. Chem. 276, 8705-8712.

Porter, R.K., 2001. Mitochondrial proton leak: a role for uncoupling proteins 2 and 3? Biochim. Biophys. Acta 1504, 120-127.

Pörtner, H.O., 2002. Physiological basis of temperature-dependent biogeography: trade-offs in muscle design and performance in polar ectotherms. J. Exp. Biol. 205, 2217-2230.

Pörtner, H.O., van Dijk, P.L.M., Hardewig, I., Sommer, A., 2000. Levels of metabolic cold adaptation: tradeoffs in eurythermal and stenothermal ectotherms. In: Davison, W., Williams, C.W. (Eds.), Antarctic Ecosystems: Models for a Wider Understanding. Caxton Press, Christchurch, New Zealand, pp. 109-122.

Pörtner, H.O., Lucassen, M., Storch, D., 2005. Metabolic biochemistry: its role in thermal tolerance and in the capacities of physiological and ecological function. In: Farrell, A.P., Steffensen, J.F. (Eds.), The Physiology of Polar Fishes, vol. 21. Elsevier Academic Press, San Diego, pp. 79-154.

Raimbault, S., Dridi, S., Denjean, F., Lachuer, J., Couplan, E., Bouillaud, F., Bordas, A., Duchamp, C., Taouis, M., Ricquier, D., 2001. An uncoupling protein homologue putatively involved in facultative muscle thermogenesis in birds. Biochem. J. 353, 441-444.

Richard, D., Clavel, S., Huang, Q., Sanchis, D., Ricquier, D., 2001. Uncoupling protein 2 in the brain: distribution and function. Biochem. Soc. Trans. 29, $812-817$.

Ricquier, D., Bouillaud, F., 2000. The uncoupling protein homologues: UCP1, UCP2, UCP3, StUCP and AtUCP. Biochem. J. 345 (Pt 2), 161-179.

Rolfe, D.F., Brand, M.D., 1996. Proton leak and control of oxidative phosphorylation in perfused, resting rat skeletal muscle. Biochim. Biophys. Acta $1276,45-50$.

Rolfe, D.F., Newman, J.M., Buckingham, J.A., Clark, M.G., Brand, M.D., 1999. Contribution of mitochondrial proton leak to respiration rate in working skeletal muscle and liver and to SMR. Am. J. Physiol. 276, C692-C699.
Sambrook, J., Fritsch, E.F., Maniatis, T., 1989. Molecular Cloning. A Laboratory Manual. Cold Spring Harbor Laboratory Press, New York.

Skulachev, V.P., 1998. Uncoupling: new approaches to an old problem of bioenergetics. Biochim. Biophys. Acta, Bioenerg. 1363, 100-124.

Sokolova, I.M., Sokolov, E.P., 2005. Evolution of mitochondrial uncoupling proteins: novel invertebrate UCP homologues suggest early evolutionary divergence of the UCP family. FEBS Lett. 579, 313-317.

Somero, G.N., DeVries, A.L., 1967. Temperature tolerance of some Antarctic fishes. Science 156, 257-258.

Stevens, E.D., Kanwisher, J.W., Carey, F.G., 2000. Muscle temperature in freeswimming giant Atlantic bluefin tuna (Thunnus thynnus L.). J. Therm. Biol. 25, 419-423.

Stuart, J.A., Harper, J.A., Brindle, K.M., Brand, M.D., 1999. Uncoupling protein 2 from carp and zebrafish, ectothermic vertebrates. Biochim. Biophys. Acta 1413, 50-54.

Talbot, D.A., Duchamp, C., Rey, B., Hanuise, N., Rouanet, J.L., Sibille, B., Brand, M., 2004. Uncoupling protein and ATP/ADP carrier increase mitochondrial proton conductance after cold adaptation of king penguins. J. Physiol. 558, 123-135.

Vianna, C.R., Hagen, T., Zhang, C.Y., Bachman, E., Boss, O., Gereben, B., Moriscot, A.S., Lowell, B.B., Bicudo, J.E., Bianco, A.C., 2001. Cloning and functional characterization of an uncoupling protein homolog in hummingbirds. Physiol. Genomics 5, 137-145.

Walker, J.E., 1992. The mitochondrial transporter family. Curr. Opin. Struct. Biol. 2, 519-526.

Wodtke, E., 1981a. Temperature adaptation of biological membranes: compensation of the molar activity of cytochrome $c$ oxidase in the mitochondrial energy-transducing membrane during thermal acclimation of the carp (Cyprinus carpio L.). Biochim. Biophys. Acta 640, 710-720.

Wodtke, E., 1981b. Temperature adaptation of biological membranes. The effects of acclimation temperature on the unsaturation of the main neutral and charged phospholipids in mitochondrial membranes of the carp (Cyprinus carpio L.). Biochim. Biophys. Acta 640, 698-709.

Wojtczak, L., Wiecedilckowski, M.R., 1999. The mechanisms of fatty acid-induced proton permeability of the inner mitochondrial membrane. J. Bioenerg. Biomembranes 31, 447-455. 